\title{
Hemşirelerin Yaşam Kaliteleri İle Tükenmişlik Düzeylerinin Değerlendirilmesine Yönelik Bir Araştırma*
}

\section{A Research on the Evaluation of Life Quality and Burnout Levels of Nurses'}

\author{
Mustafa Durmuş, a,** Abdullah Gerçek, ${ }^{\mathrm{b}}$ Necmettin Çiftci ${ }^{\mathrm{c}}$ \\ ${ }^{a}$ Öğr. Gör., Muş, Alparslan Üniversitesi, Sağlık Yüksekokulu, Hemşirelik Bölümü, 49100, Muş/Türkiye. \\ ORCID: 0000-0002-7559-4187
}

b Öğr. Gör., Muş, Alparslan Üniversitesi, Sağlık Yüksekokulu, Hemşirelik Bölümü, 49100, Muş/Türkiye. ORCID: 0000-0001-8675-1224

c Öğr. Gör., Muş, Alparslan Üniversitesi, Sağlık Hizmetleri Meslek Yüksekokulu, Sağlık Bakım Hizmetleri Bölümü, 49100, Muş/Türkiye. ORCID: 0000-0002-4713-4212

\section{MAKALE BILGİSI}

Makale Geçmişi:

Başvuru tarihi: 04 Temmuz 2017

Düzeltme tarihi: 26 Ocak 2018

Kabul tarihi: 11 Şubat 2018

\section{Anahtar Kelimeler:}

Hemşire

Tükenmişlik

Yaşam Kalitesi

\section{ARTICLE INFO}

\section{Article history:}

Received 04 July 2017

Received in revised form 26 January 2018 Accepted 11 February 2018

\section{Keywords:}

Nurses

Burnout

Quality of Life

\section{ÖZ}

Bu çalışma, hemşirelerin yaşam kalitesi ile tükenmişlik düzeyleri arasındaki ilişkinin incelenmesi amacıyla yapılmıştır. Araştırma, Muş devlet hastanesinde yapılmıştır. Araştırmanın örneklemini Muş ilinde çalışan 151 hemşire çalışanı oluşturmuştur. Veri toplamada "Hemşirelerin sosyodemografik özelliklerine ait sorular", "Maslach Tükenmişlik Ölçeği”" ve "WHOQOL-BREF(TR) Yaşam Kalitesi Ölçeği" kullanılmıştır. Verilerin değerlendirmesinde frekans ve yüzdelik hesaplama, verilerin dağılımı, bağımsız gruplarda t testi, spearman koreleasyon analizi, tek yönlü varyans analizi testi kullanılmıştır. WHOQOL-BREF-TR ile MTÖ arasında güçlü negatif yönde anlamlı bir ilişki saptanmıştır $(p<0.001)$. Bu çalışmada, hemşirelerin tükenmişlik ve yaşam kalitesinin düşük olduğu, bazı değişkenlerin yaşam kalitesini olumsuz yönde etkilediği belirlenmiştir.

\section{A B S T R A C T}

This study was conducted in order to examine the relationship between quality of life and burnout levels of nurses. The research was conducted at Muş State Hospital between August-September 2016. In the research, sampling method was not used and it was carried out with 151 nurses constituting 60, 6\% of nurses in Muş State Hospital. For data collection" Questions of sociodemographic characteristics of nurses", "Maslach Burnout Inventory (MBI)" " and the Turkish version of the "World Health Organization Quality of Life Instrument Scale (WHOQOL-BREFTR)" were used. To assess the data the frequency and percentage calculations, the distribution of data, kolmogorov smirnov, independent Samples t-test, Pearson Correlated analysis and one way ANOVA test were used. In this study, there was a strong negative statistically significant relationship between the WHOQOL-BREF-TR and MBI $(\mathrm{p}<0.001)$. In this study, it was determined that burnout and quality of life of nurses were low and some variables affected quality of life negatively.

\section{Giriş}

Yaşam kalitesi, yaşamdan duyulan hoşnutluk ve mutluluk olarak tanımlanabileceği gibi bireylerin kültür ve değerler sistemi içinde, kendi durumlarını algılayış biçimidir diye de tanımlanabilir. Yaşam kalitesinin kapsamında, insanların fiziksel fonksiyonları, psikolojik durumları, aile içinde ve dışındaki sosyal ilişkileri, çevreyle etkileşimleri ve inançları yer almaktadır (Arslantas vd., 2009: 127-131).

Yaşamın bütün olması, çalışma ve yaşama koşullarının, dolayısıyla çalışma ve yaşam kalitesinin birbirinden ayrı düşünülmesini imkânsız hale getirmektedir. Bunun nedeni, çalışma ve yaşama koşulları arasında çok yönlü, sıkı

\footnotetext{
* Bu çalışma, 6-9 Kasım 2016 tarihlerinde Manisa'da düzenlenen IV.Uluslararası VIII. Ulusal Psikiyatri Hemşireliği Kongresi’nde poster bildiri olarak sunulmuştur.

** Sorumlu yazar/Corresponding author.

e-posta: m.durmus@alparslan.edu.tr
} 
etkileşimin bulunmasıdır. Bu nedenle çalışma yaşamı kalitesi, yaşam kalitesinin sağlanması bakımından önemlidir (Yüksel, 2011: 47-58). Konu hemşireler üzerinde incelendiğinde bu meslek grubunun çalışma yaşamlarında pek çok zorlu süreçle karşı karşıya kaldığı muhakkaktır. Bu sebeple bireyin kendi yaşamını değerlendirmesine dayanan, özel alg1, duygu ve biliş süreçlerinin bir bütünü olarak tanımlanan ve motivasyonu önemli ölçüde etkilediği düşünülen yaşam kalitesi büyük önem taşımaktadır. İstenilen nitelikte sağlık hizmeti verilebilmesi bu hizmeti sunanların niteliğiyle yakından ilişkilidir. $\mathrm{Bu}$ anlamda çalışanların yaşama ve çalışma koşullarına ilişkin sorunların giderilmesi sağlık hizmetinin aksaklıklarının azaltılması açısından önemlidir (Şahin vd., 2014: 81-92).

Yaşam kalitesi kavramı tıbbi tanı ve laboratuvar işlemleriyle ölçülen bir nicelik değil, subjektif olarak yaşantılanan bir nitelik olarak belirtilmektedir. Yaşam kalitesi geniş bir kavram olup; bireyin fiziksel sağlığı, psikolojik durumu, bağımsızlık düzeyi, sosyal ilişkileri ve çevresindeki özelliklerden etkilenir (Ergün vd., 2013). Sağlıkta iyilik halinin ölçülebilmesinde yaşam kalitesi kavramı geliştirilmiştir. Yaşam kalitesi bireyin fiziksel işlevlerini, ruhsal durumunu, aile içindeki ve dişındaki toplumsal ilişkilerini, cevreden etkilenilmişlik düzeylerini kapsar ve bu durumun bireyin işlevselliğini ne derece etkilediğini gösterir (Testa ve Simonson, 1996: 835-840).

Modern zamanların önemli fenomenlerinden biri olarak bilinen tükenmişliğin "Mesleki bir tehlike" olarak ilk klinik tanımlamalarından biri, 1974 yılında, Freudenberger (1974, 1975) tarafindan yapılmıştır (Suran ve Sheridan, 1985: 741). Tükenmişlikle ilgili günümüzde en yaygın kabul gören tanım, konuyla ilgili çalışan araştırmacılar arasında en önemli isim olarak anılan ve Maslach Tükenmişlik Envanterini geliştiren Christina Maslach'a aittir. Maslach, tükenmişlik kavramını; duygusal tükenme (emotional exhaustion), duyarsızlaşma (depersonalization) ve kișisel başarıya (personel accomplishment) ilişkin duyguları kategorize eden üç ayrı boyutta ele almaktadır (Ergin, 1992). Başka bir deyişle Maslach'a göre tükenmişlik “İşi gereği insanlarla yoğun bir ilişki içerisinde olanlarda görülen duygusal tükenme, duyarsızlaşma; tükenmişliğin kişiler arası boyutunu temsil etmekte ve bireylere negatif, katı tutumları ve işe karşı tepkisizleşmeyi belirtmektedir ve düşük kişisel başarl hissi; Kişinin kendisini olumsuz değerlendirme eğiliminde olması şeklinde tanımlanmaktadır (Maslach vd., 2001; Wright ve Bonett, 1997).

İnsanlarla yüz yüze çalışan, doğrudan insana hizmet eden ve hizmetin kalitesinde insan unsurunun çok önemli bir yere sahip olduğu mesleklerde (doktor, hemşire, öğretmen, polis, avukat vb.) tükenmişliğin daha s1k görüldüğü bildirilmiştir (Altay vd., 2010; Barron ve West, 2007).

Araştırmanın Soruları aşağıda belirtilmektedir:

(i) Hemşirelerin yaşam kalitesi ve tükenmişlik düzeyleri nasildır?

(ii) Hemşirelerin yaşam kalitesi ile tükenmişlik düzeyi arasında ilişki var mıdır?

(iii) Hemşirelerin sosyodemografik özelliklerine göre yaşam kalitesi ve tükenmişlik düzeyleri arasında bir fark var midir?

\section{Yöntem}

\subsection{Araştırmanın amacı}

Bu çalışma, Muş Devlet Hastanesi'nde çalışan hemşirelerin yaşam kalitesi ile tükenmişlik düzeyleri arasındaki ilişkinin incelenmesi amacıyla yapılmıştır.

\subsection{Evren ve Örneklem}

Araştırma, Ağustos-Eylül 2016 tarihleri arasında Muş devlet hastanesinde yapılmıştır. Araştırmada örnekleme yöntemi kullanılmayarak Muş Devlet Hastanesindeki hemşirelerin \%60,6 'nı oluşturan 151 hemşire ile yürütülmüştür.

\subsection{Veri Toplama Arac1}

\subsubsection{Tanımlayıcı Form}

Yaş, cinsiyet, medeni durum, eğitim düzeyi, çalıştığı birim, çalışma şekli, mesleği seçme durumundan oluşan sosyodemografik ve mesleki özelliklerle ilgili toplam 16 soru içermektedir.

\subsubsection{Dünya Sağllk Örgütü Yaşam Kalitesi Ölçeği Kısa Formu Türkçe Versiyonu (WHOQOL-BREF-TR)}

Sağlıkla ilişkili yaşam kalitesi ölçeği DSÖ tarafından geliştirmiş,(Eser vd., 1999a) Eser ve arkadaşları tarafından geçerlik ve güvenirliği yapılmıştır. Ölçeğin uzun (WHOQOL-100) ve k1sa (WHOQOL-27) formu olmak üzere iki surumu vardır. Ölçek bedensel, ruhsal, sosyal ve çevresel iyilik hallerini ölçmekte ve 26 sorudan oluşmaktadır. Türkiye surumu (27. soru ulusal sorudur) kullanıldığında Çevre alan skoru çevre-TR olarak adlandırılır. Bu durumda Çevre-TR alan skoru çevre skoru yerine kullanılır. Ölçek yaşlı olmayan yetişkinlere uygulanabilmektedir (Aydemir ve Köroğlu, 2007). Ölçek sağlık çalışanlarında da uygulanmıştır (Eser vd., 1999b: 647). Her bir alan, birbirinden bağımsız olarak kendi alanındaki yaşam kalitesini ifade ettiği için, alan puanları 420 arasında hesaplanmaktadır. Puan arttıkça yaşam kalitesi artmaktadır (Aydemir ve Köroğlu, 2007; Eser vd., 1999b: 647). Ölçeğin orijinalinde güvenirliğini belirlemek için hesaplanan Cronbach alfa iç tutarlık katsayısı $\alpha=0,89$, yaptığımız bu çalışmanın Cronbach alfa iç tutarlık katsayısı ise $\alpha=0,86$ olarak bulunmuştur.

\subsubsection{Maslach Tükenmişlik Ölçeği (MTÖ)}

Maslach ve Jackson (1981) tarafından geliştirilmiş, Türkiye de geçerlik ve güvenirlik çalışması Olcay (2001) ve Ergin (1992) tarafından yapılmıştır. Ölçek 5'li Likert tipinde (0: Hiçbir zaman, 1: Çok nadir, 2: Bazen, 3: Çoğu zaman, 4: Her zaman) 22 sorudan oluşmaktadır. Duygusal Tükenme (DT, 9 madde), Duyarsızlaşma (D, 5 madde) ve Kişisel Başarı Eksikliği (KBE, 8 madde) olmak üzere üç boyutu vardır. DT, kişinin yaptığı iş nedeniyle emosyonel olarak kendini aşırı yüklenmiş hissetmesidir ve tükenmişliğin en önemli belirleyicisidir. D, bireyin hizmet verdiği kișilerin birer birey olduklarını dikkate almaksızın duygudan yoksun bicimde tutum ve davranışlar sergilemesidir. KBE ise, sorunun başarı ile üstesinden gelememe ve kendini yeterli görmeme olarak tanımlanır. Alt ölçek puanları DT ve D için yukarıda belirtildiği gibi, KBE için ise tersine puanlanmaktadır 
(Hiçbir zaman: 4, Her zaman: 0). DT ve D alt ölçekleri olumsuz, KBE ise olumlu ifadelerden oluşan Kişisel Başarının tersine çevrilerek puanlanması nedeniyle KBE olarak ifade edilmektedir. Alt ölçeklerden elde edilen puanlar için kesme değeri olmadı̆̆ından tükenme var ya da yok biçiminde bir ayırım yapılamamaktadır. Tükenmişliği yaşamakta olan bireylerde DT (0-36), D (0-20) ve KBE (032) puanlarının yüksek olması beklenmektedir( Ergin, 1992). Ölçeğin orijinalinde güvenirliğini belirlemek için hesaplanan Cronbach alfa iç tutarlık katsayısı $\alpha=0,93$, yaptığımız bu çalışmanın Cronbach alfa iç tutarlık katsayısı ise $\alpha=0,80$ olarak bulunmuştur.

2.4. İstatistiksel Değerlendirme, Etik İlkeler ve Çalışmanın Sınırlılıkları

Verilerin değerlendirilmesinde, verilerin normal dağılım gösterip göstermediği kolmogorov smirnov testi ile sınanmış ve normal dağılıma uygun olduğu tespit edilmiştir. Hemşirelerin tanıtıcı özelliklerini incelemek amaciyla frekans ve yüzdelik hesaplama, tanıtıcı özellikler ile yaşam kalitesi ve tükenmişlik düzeyleri arasında önemli bir fark olup olmadığının belirlenmesinde one way anova ve t testi, yaşam kalitesi ölçeği ile tükenmişlik envanteri arasındaki ilişkiyi belirlemek için de Pearson Korelasyon analizi yapılmıştır.

Araştırmaya başlamadan önce, ilgili üniversitenin Etik Kurul Başkanlığı'ndan etik açıdan uygunluk ve hastaneden araştırmanın yapılması için izin alınmıştır. Araştırmaya katılan hemşireler bilgilendirilmiş ve sözlü onam alınmıştır. Ayrıca, araştırmanın tek kurumda yapılması sınırlılığıdır.

\section{Bulgular}

\subsection{Hemşirelerin Tanımlayıcı Özellikleri}

Araştırmaya katılan hemşirelerin çoğunluğu 18-25 yaş aralığında olduğu, çalışanların \% 69,5'i kadın, \% 41,1'i lisans mezunu ve \% 51 bekâr olup en büyük grubu oluşturmaktadırlar. Hemşirelerin \% 26,5'i yoğun bakımda, $\%$ 51,7'si 5 ve 5 yıldan daha az çalışmakta, \%39,7 aynı serviste 4-6 hemşire ile çalışmakta, \% 50,3'ünün hastanede çalıştığ1 servis sıklıkla değişmemektedir. Hemşirelerin \% 80,1'i gece nöbetine kaldığ1, \% 69,5'inin 24 saat nöbet tuttuğu, \% 76,2'sinin aylık çalışma süresini aştığ 1 , \% 54,3'ünün sağlığını orta derecede hissettiği \% 61,6'sının aylık gelirinin 3000-4000 arası olduğu ve \% 53,6'sının kendi mesleğini isteyerek seçmediği belirlenmiştir (Tablo 1).

Tablo 1. Hemşirelerin Tanımlayıcı Özellikleri $(n=151)$

\begin{tabular}{ccc}
\hline Değişkenler & Sayı & Yüzde \\
\hline Yaş gurubu & & \\
\hline $18-25$ & 65 & 43 \\
$26-32$ & 52 & 34.4 \\
$33-38$ & 27 & 17.9 \\
$39-45$ & 5 & 3.3 \\
46 ve $\uparrow$ & 2 & 1.3 \\
\hline Cinsiyet & & \\
\hline Kadın & 105 & 69.5 \\
Erkek & 46 & 30.5 \\
\hline Eğitim durumu & & \\
\hline Lise & 34 & 22.5 \\
Ön lisans & 44 & 29.1
\end{tabular}

\begin{tabular}{|c|c|c|}
\hline $\begin{array}{l}\text { Lisans } \\
\text { Lisansüstü } \\
\end{array}$ & $\begin{array}{l}62 \\
11 \\
\end{array}$ & $\begin{array}{c}41.1 \\
7.3 \\
\end{array}$ \\
\hline \multicolumn{3}{|l|}{ Medeni durum } \\
\hline Evli & 74 & 49 \\
\hline Bekar & 77 & 51 \\
\hline \multicolumn{3}{|l|}{ Çalıştığ 1 bölüm } \\
\hline Dahili birimler & 30 & 19.9 \\
\hline Cerrahi birimler & 36 & 23.8 \\
\hline Acil servis & 23 & 15.2 \\
\hline Yoğun bakım & 40 & 26.5 \\
\hline Diğer & 22 & 14.6 \\
\hline \multicolumn{3}{|l|}{ Meslekte çalışma süresi } \\
\hline 5 ve $\downarrow$ & 78 & 51.7 \\
\hline $6-10$ & 49 & 32.5 \\
\hline $11-15$ & 12 & 7.9 \\
\hline 16 ve $\uparrow$ & 12 & 7.9 \\
\hline \multicolumn{3}{|c|}{ Çalıştığı klinikteki hemşire sayısı } \\
\hline $1-4$ & 17 & 11.3 \\
\hline $4-6$ & 60 & 39.7 \\
\hline $6-8$ & 45 & 29.8 \\
\hline 8 ve $\uparrow$ & 29 & 19.2 \\
\hline \multicolumn{3}{|c|}{ Kurumdaki servis değişikliği } \\
\hline Evet & 75 & 49.7 \\
\hline Hayır & 76 & 50.3 \\
\hline \multicolumn{3}{|l|}{ Çalışma şekli } \\
\hline Gündüz & 30 & 19.9 \\
\hline Nöbet & 121 & 80.1 \\
\hline \multicolumn{3}{|l|}{ Günlük çalışma süresi } \\
\hline 8 saat & 33 & 21.9 \\
\hline 16 saat & 13 & 8.6 \\
\hline 24 saat & 105 & 69.5 \\
\hline \multicolumn{3}{|c|}{ Aylık çalışma süresini aşma durumu } \\
\hline Evet & 115 & 76.2 \\
\hline Hayır & 36 & 23.8 \\
\hline \multicolumn{3}{|c|}{ Kendisini değerlendirme durumu } \\
\hline İyi & 39 & 25.8 \\
\hline Kötü & 30 & 19.9 \\
\hline İdare eder & 82 & 54.3 \\
\hline \multicolumn{3}{|l|}{ Aylik gelir } \\
\hline $2000-3000$ & 36 & 23.8 \\
\hline $3000-4000$ & 93 & 61.6 \\
\hline 4000 ve $\uparrow$ & 22 & 14.6 \\
\hline \multicolumn{3}{|l|}{ Meslek seçme durumu } \\
\hline İsteyerek seçme & 70 & 46.4 \\
\hline Başka nedenler & 81 & 53.6 \\
\hline
\end{tabular}

\subsection{Tükenmişlik ve Yaşam Kalitesi Düzeyi}

Çalışmada, Duygusal Tükenme puan ortalaması 30.06 \pm 7.62 ; Duyarsızlaşma 13.18 \pm 4.80 ; Kişisel Başarısızlık 28.53 \pm 5.72 ; WHOQOL-BREF-TR Bedensel alan 20.00 \pm 3.70 ; Ruhsal alan 19.54 \pm 3.30 ; Sosyal alan 9.58 \pm 2.33 ; Çevresel alan-TR 23.46 \pm 4.27 olarak belirlenmiştir (Tablo 2). 
Tablo 2. Hemşirelerin MTÖ, WHOQOL- BREF-TR Ölçeklerinden Aldıkları Ortalama Puanlar $(n=151)$

\begin{tabular}{lccc}
\hline \multicolumn{1}{r}{ MTÖ } & $\begin{array}{c}\text { Alınabilecek } \\
\text { Puan Aralığ } 1\end{array}$ & $\begin{array}{c}\text { Alınan Puan } \\
\text { Aralığ } 1\end{array}$ & $\begin{array}{c}\text { Ort. } \\
\text { (SS) }\end{array}$ \\
\hline DT & $0-36$ & $9-45$ & 30.06 \\
& & & $\begin{array}{c}7.62) \\
13.18\end{array}$ \\
D & $0-20$ & $5-24$ & $(4.80)$ \\
KBE & $0-32$ & $12-40$ & 28.53 \\
WHOQOL- & & & $(5.72)$ \\
BREF-TR & & & \\
Bedensel & & & \\
& & $8-29$ & $(3.00$ \\
Ruhsal & & & 19.54 \\
& & $9-27$ & $(3.30)$ \\
Sosyal & & & 9.58 \\
& & $3-15$ & $(2.33)$ \\
Çevre-TR & & & 23.46 \\
& & $9-35$ & $(4.27)$ \\
\hline
\end{tabular}

Yapılan korelasyon analizi sonucunda WHOQOL-BREFTR ile DT, D, arasında zayıf negatif yönde bir ilişki, KBE ile arasında orta pozitif yönde bir ilişki saptanmıştır $(\mathrm{p}<0.001)$, (Tablo 3).

Tablo 3. Hemşirelerin MTÖ, WHOQOL- BREF-TR Ölçekleri Arasındaki İlişki

\begin{tabular}{lcccc}
\hline \multicolumn{5}{c}{ WHOQOL- BREF-TR } \\
\hline & Bedensel & Ruhsal & Sosyal & Çevre \\
& $\mathrm{r}^{*}$ & $\mathrm{r}^{*}$ & $\mathrm{r}^{*}$ & $\mathrm{r}^{*}$ \\
DT & $-0.152^{* *}$ & $-0.227^{* *}$ & $-0.259^{* *}$ & $-0.280^{* *}$ \\
D & $-0.780^{* *}$ & $-0.326^{* *}$ & $-0.132^{* *}$ & $-0.180^{* *}$ \\
KEB & $0.193^{* *}$ & $0.205^{* *}$ & $0.150^{* *}$ & $0.133^{* *}$ \\
\hline
\end{tabular}

* Pearson korelasyon analizi, $* * \mathrm{p}<0.05$

Hemşirelerin WHOQOL- BREF-TR puan ortalamaları ele alındığında; yaş grupları, cinsiyet, eğitim, medeni durum, meslekteki çalışma süresi, çalıştığı birimdeki hemşire sayısı, kurumdaki servis değişikliği, çalışma şekli, günlük çalışma süresi ve aylık çalışma süresinin üstünde çalışma durumu puan ortalamasının anlamlı olmadığı, fakat çalıştığı bölüm, sağlı̆̆ı değerlendirme, aylık gelir ve mesleğini seçme durumu puan ortalamaları arasinda anlamlı bir farklılık bulunmuştur (Tablo 4).

Maslach Tükenmişlik Envanteri puan ortalamaları ele alındığında ise, yaş grupları, cinsiyet, eğitim, medeni durum, meslekteki çalışma süresi, çalıştığı birimdeki hemşire sayısı, kurumdaki servis değişikliği, çalışma şekli, günlük çalışma süresi ve aylık çalışma süresini aşma durumuna göre puan ortalamaları arasında anlamlı farklılıklar olmadığı, fakat sağlığı değerlendirme ve mesleğini seçme durumu puan ortalamaları arasında anlamlı farklılıklar olduğu bulunmuştur. Hemşirelerin yaşam kalitesi çalıştığı birime göre incelendiğinde farkın hangi gruptan kaynakladığını belirlemek için yapılan ileri analizlerden Post Hoc Tukey testi sonucunda dahili, acil, yoğun bakım birimlerinin puan ortalamaları cerrahi biriminde çalışanlardan düşük olduğu belirlenmiştir. Hemşirelerin yaşam kalitesi ve tükenmişlik düzeyleri sağlık durumlarını değerlendirmesi incelendiğinde farkın hangi gruptan kaynakladığını belirlemek için yapılan ileri analizlerden Post Hoc Tukey testi sonucunda kötü ve idare eder şeklinde ifade edenlerin puan ortalamaları, iyi olarak belirtenlerden düşük olduğu bulunmuştur (Tablo 4).

Tablo 4. Hemşirelerin Yaşam Kalitesi ve Tükenmişlik Puanları ( $\mathrm{n}=$ 151)

\begin{tabular}{ccc}
\hline $\begin{array}{c}\text { Sosyo- } \\
\text { demografik }\end{array}$ & $\begin{array}{c}\text { WHOQOL- } \\
\text { BREF-TR } \\
\text { Ort } \pm \text { SS }\end{array}$ & $\begin{array}{c}\text { Maslach Tükenmişlik } \\
\text { Envanteri } \\
\text { Ort } \pm \text { SS }\end{array}$ \\
\hline Yaş grubu & & \\
\hline $18-25$ & $72.80 \pm 10.96$ & $63.55 \pm 11.48$ \\
$26-32$ & $72.21 \pm 11.39$ & $63.26 \pm 10.22$ \\
$33-38$ & $74.11 \pm 9.58$ & $61.07 \pm 14.74$ \\
$39-45$ & $69.20 \pm 19.95$ & $60.20 \pm 11.25$ \\
46 ve $\uparrow$ & $64.00 \pm 2.82$ & $49.50 \pm 10.60$ \\
Test ve & $\mathrm{F}=, 554, \mathrm{p}=.697^{*}$ & $\mathrm{~F}=, 938, \mathrm{p}=.444^{*}$ \\
anlamlılık & &
\end{tabular}

\begin{tabular}{ccc}
\hline Cinsiyet & & \\
\hline Kadın & $72.69 \pm 10.26$ & $63.36 \pm 12.25$ \\
Erkek & $72.36 \pm 13.01$ & $61.23 \pm 10.32$ \\
Test ve & $\mathrm{t}=-0,165$, & $\mathrm{t}=-1,026, \mathrm{p}=0.307^{*}$ \\
anlamlılık & $\mathrm{p}=0.869^{*}$ &
\end{tabular}

\begin{tabular}{lcc}
\hline Eğitim durumu & & \\
\hline Lise & $72.02 \pm 8.25$ & $64.32 \pm 11.88$ \\
Ön lisans & $71.09 \pm 11.77$ & $62.15 \pm 12.65$ \\
Lisans & $73.16 \pm 12.14$ & $62.32 \pm 11.22$ \\
Lisansüstü & $77.18 \pm 10.10$ & $61.18 \pm 10.98$
\end{tabular}

$\begin{aligned} & \text { Test ve } \\ & \text { anlamlilik }\end{aligned} \quad \mathrm{F}=, 972, \mathrm{p}=.408 * \quad \mathrm{~F}=, 274, \mathrm{p}=.844 *$

\begin{tabular}{ccc}
\hline Medeni durum & & \\
\hline Evli & $72.77 \pm 11.95$ & $62.72 \pm 11.71$ \\
Bekar & $72.29 \pm 10.45$ & $63.08 \pm 11.63$
\end{tabular}

\begin{tabular}{|c|c|}
\hline ve & $\mathrm{t}=.259, \mathrm{p}=.796^{*}$ \\
\hline
\end{tabular}

\begin{tabular}{ccc}
\hline Çalıştı̆̆ bölüm & & \\
\hline $\begin{array}{l}\text { Dahili } \\
\text { birimler }\end{array}$ & $80.46 \pm 12.85$ & $74.06 \pm 13.48$
\end{tabular}

$\begin{array}{lll}\text { Cerrahi } & 85.69 \pm 9.97 & 70.41 \pm 8.94\end{array}$

$\begin{array}{lll}\text { birimler } & 85.69 \pm 9.97 & 70.41 \pm 8.94 \\ \text { Acil } & 83.47 \pm 9.86 & 70.34 \pm 15.43\end{array}$

$\begin{array}{lll}\text { Acil servis } & 83.47 \pm 9.86 & 70.34 \pm 15.43\end{array}$

Yoğun bakım $\quad 77.72 \pm 12.70 \quad 70.95 \pm 12.70$

$\begin{array}{lll}\text { Diğer } & 78.90 \pm 14.49 & 73.95 \pm 13.69\end{array}$

$\begin{array}{lcl}\text { Test ve } & \mathrm{F}=2,526, & \mathrm{~F}=, 624, \mathrm{p}=.646^{*} \\ \text { anlamlilik } & \mathrm{p}=.043^{*}\end{array}$

\begin{tabular}{ccc}
\hline \multicolumn{2}{l}{ Meslekte çalışma süresi } & \\
\hline 5 ve $\downarrow$ & $81.08 \pm 11.91$ & $72.48 \pm 10.85$ \\
$6-10$ & $81.93 \pm 11.94$ & $71.30 \pm 13.39$ \\
$11-15$ & $77.33 \pm 15.13$ & $70.58 \pm 14.26$ \\
16 ve $\uparrow$ & $83.00 \pm 13.61$ & $67.41 \pm 18.35$
\end{tabular}

Test ve $\quad \mathrm{F}=, 540, \mathrm{p}=.656^{*} \quad \mathrm{~F}=, 658, \mathrm{p}=.579^{*}$

\begin{tabular}{ccc}
\hline Çalıştığ klinikteki hemşire sayıs & \\
\hline $1-4$ & $79.88 \pm 10.80$ & $69.47 \pm 14.20$ \\
$4-6$ & $81.36 \pm 13.72$ & $71.83 \pm 12.49$ \\
$6-8$ & $82.30 \pm 11.51$ & $72.21 \pm 10.53$ \\
8 ve $\uparrow$ & $79.92 \pm 11.38$ & $72.39 \pm 15.41$
\end{tabular}

$\begin{aligned} & \text { Test ve } \\ & \text { anlamlilik }\end{aligned} \mathrm{F}=, 289, \mathrm{p}=.833^{*} \quad \mathrm{~F}=, 226, \mathrm{p}=.878^{*}$

\begin{tabular}{ccc}
\hline \multicolumn{2}{l}{ Kurumdaki servis değişikliği } & \\
\hline Evet & $82.24 \pm 11.63$ & $70.69 \pm 13.05$ \\
Hayır & $80.21 \pm 12.85$ & $72.86 \pm 12.20$
\end{tabular}

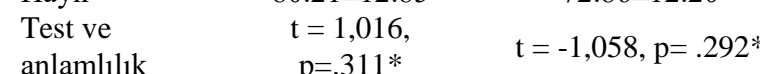
anlamlilik $\quad \mathrm{p}=.311 * \quad \mathrm{t}=-1,058, \mathrm{p}=.292^{*}$

\begin{tabular}{ccc}
\hline Çalışma şekli & & \\
\hline Gündüz & $74.83 \pm 11.62$ & $60.30 \pm 11.11$ \\
Nöbet & $72.04 \pm 10.98$ & $63.31 \pm 11.81$
\end{tabular}

$\begin{array}{lll}\text { Test ve } & \mathrm{t}=-1,232, & \mathrm{t}=1,265, \mathrm{p}=.208^{*}\end{array}$

\begin{tabular}{ccc} 
anlamlılık & $\mathrm{p}=.220^{*}$ & \\
\hline Günlük çalışma süresi & & \\
\hline 8 Saat & $72.72 \pm 10.92$ & $62.03 \pm 10.66$ \\
16 Saat & $70.92 \pm 10.73$ & $65.00 \pm 10.45$ \\
24 Saat & $72.76 \pm 11.32$ & $62.64 \pm 12.21$
\end{tabular}




\begin{tabular}{|c|c|c|}
\hline $\begin{array}{l}\text { Test ve } \\
\text { anlamll11k }\end{array}$ & $\begin{array}{l}\mathrm{F}=, 166 \\
\mathrm{p}=.847 *\end{array}$ & $\mathrm{~F}=, 235, \mathrm{p}=.791^{*}$ \\
\hline \multicolumn{3}{|c|}{ Aylık çalışma süresini aşma durumu } \\
\hline Evet & $81.36 \pm 12.75$ & $71.91 \pm 13.51$ \\
\hline Hayır & $80.75 \pm 10.71$ & $71.38 \pm 9.44$ \\
\hline $\begin{array}{l}\text { Test ve } \\
\text { anlamlilık }\end{array}$ & $\mathrm{t}=, 262, \mathrm{p}=.794^{*}$ & $\mathrm{t}=, 216, \mathrm{p}=.829^{*}$ \\
\hline \multicolumn{3}{|c|}{ Sağlık değerlendirme durumu } \\
\hline İyi & $79.00 \pm 10.90$ & $55.56 \pm 10.88$ \\
\hline Kötü & $67.26 \pm 12.78$ & $66.13 \pm 10.29$ \\
\hline İdare eder & $71.50 \pm 9.15$ & $64.86 \pm 11.25$ \\
\hline $\begin{array}{l}\text { Test ve } \\
\text { anlamlil1k }\end{array}$ & $\begin{array}{c}\mathrm{F}=11,765 \\
\mathrm{p}=.000^{*}\end{array}$ & $\mathrm{~F}=11,299, \mathrm{p}=.000^{*}$ \\
\hline \multicolumn{3}{|l|}{ Aylık gelir } \\
\hline $2000-3000$ & $69.50 \pm 11.67$ & $64.27 \pm 10.75$ \\
\hline $3000-4000$ & $73.01 \pm 10.92$ & $62.19 \pm 12.25$ \\
\hline 4000 ve $\uparrow$ & $75.90 \pm 10.29$ & $62.36 \pm 11.07$ \\
\hline $\begin{array}{l}\text { Test ve } \\
\text { anlamlilık }\end{array}$ & $\begin{array}{c}\mathrm{F}=2,479 \\
\mathrm{p}=.047 *\end{array}$ & $\mathrm{~F}=, 420, \mathrm{p}=.658^{*}$ \\
\hline \multicolumn{3}{|c|}{ Meslek seçme durumu } \\
\hline $\begin{array}{l}\text { İsteyerek } \\
\text { seçme }\end{array}$ & $75.40 \pm 10.34$ & $61.00 \pm 12.18$ \\
\hline $\begin{array}{l}\text { Başka } \\
\text { nedenler }\end{array}$ & $70.17 \pm 11.27$ & $64.19 \pm 11.14$ \\
\hline $\begin{array}{l}\text { Test ve } \\
\text { anlamlilık }\end{array}$ & $\begin{array}{l}\mathrm{t}=2.950 \\
\mathrm{p}=.004 *\end{array}$ & $\mathrm{t}=-1,684, \mathrm{p}=.044 *$ \\
\hline
\end{tabular}

\section{Tartışma}

Yapılan çalışmalar, tükenmişliğin sağlık çalışanlarını etkileyen mesleki bir sağlık sorunu olduğunu ve tükenmişlik sonucu kişilerin hizmet kalitesinin, performanslarının ve kişisel sağlıklarının etkilendiğini ortaya koymuştur. Duygusal tükenme, duyarsızlaşmanın artması ve kişisel başarıda oluşan azalma ile ortaya çıkan tükenme duygusu çalışanın iş verimini düşürmekte ve yaptığı işten tatmin olmamasına neden olarak birçok olumsuz sonucu beraberinde getirebilecek bir durum niteliğindedir. Sağlık çalışanlarının yaşam kaliteleri ile tükenmişlik düzeylerinin değerlendirilmesine yönelik yaptığımız çalışmada, MTÖ alt boyut puan ortalamaları, Duygusal Tükenme 30.06 \pm 7.62 , Duyarsızlaşma 13.18 \pm 4.80 , Kişisel Başarısızlık 28.53 \pm 5.72 olarak saptanmıştır. Bu sonuçlar çalışanların yüksek düzeyde tükenmişlik yaşadığını göstermiş olup tükenmişlik puanlarının bazı çalışma sonuçlarına göre benzer düzeyde (Zorba, 2016: 108-111; Y1lmaz, 2014: 59-63; Ergin vd., 2009: 49-64; Raftopoulos, vd., 2012: 457; Martin vd., 1997:204-209; Tunçel, vd., 2014:57) bazılarına göre ise daha yüksek düzeyde olduğu bulunmuştur (Taycan, vd., 2006: 100-108; Erol, vd., 2007:241-247; Demir, vd., 2003:807-827; Güneş ve Üstün, 2008: 48-56; Sayıl, vd., 1997: 71-77; Şenturan, vd., 2009: 33-45). Çalışan 82 hemşire ile yapılan bir çalışmada DT puanının bu çalışma puanına göre düşük, D ve KBE puanlarının benzer düzeyde olduğu belirlenmiştir (Akyüz, 2015: 21-34). Yaptığımız çalışmada mesleği isteyerek seçen hemşirelerin tükenmişlik puanlarının daha düşük olduğu saptanmıştır.

WHOQOL-BREF-TR alt boyutlarından bedensel alan 20.00 \pm 3.70 , ruhsal alan 19.54 \pm 3.30 , sosyal alan 9.58 \pm 2.33 , çevresel alan $23.46 \pm 4.27$ olarak saptanmıştır. Bu sonuçlara göre çalışanların sosyal alan dışında, genel olarak yaşam kalitesi yüksek düzeyde ve çevresel alan-TR puan ortalaması en yüksek, sosyal alan puan ortalaması en düşük olarak görülmektedir. Çalışmada bedensel alan puanlarının yüksek olması çalışma örnekleminin çoğunluğunun genç (\% 43) olmasından kaynaklandığı söylenebilir. Çalışanların çoğunluğunun (\% 76,2) aylık çalışma süresini aştığından sosyal alan puanının düşük olmasına sebep olabileceğini söyleyebiliriz. Sağlık çalışanlarıyla yapılan çalışmalarda genel olarak yaşam kalitesi orta düzeyde sonuçlar elde edilmiştir (Yıldırım ve Hacıhasanoğlu, 2011: 61-68; Kavlu ve Pınar, 2009: 1543-1555; Cimete vd., 2003: 151-158).

MTÖ toplam puan ortalaması ile yaş arasında anlamlı bir farklılık görülmemişken, yaş arttıkça katılımcıların MTÖ puan ortalamalarının azaldığı bulunmuştur. Yaş ilerledikçe çalışanların bilgi ve becerisinin artması özgüvenini arttırıcı bir faktör olup, bunun sonucunda kişisel başarı hissi artar ve tükenmişlik riski azalır denilebilir. Tükenmişliğe ilişkin yapılan araştırmalarda genç çalışanların, mesleğin ilk yıllarında beklentilerinin de yüksek olması nedeniyle daha fazla tükenmişlik hissettikleri ortaya konulmuştur (Ergin, 1995; Çimen ve Ergin, 2001: 169-176). Yapılan bazı çalışmalarda da benzer sonuçlar göstermekte iken (Kırılmaz, vd., 2003: 2-9; Say1l vd., 1997: 71-77; Brewer ve Shapard, 2004: 102-123), Engin (1996) ve Aslan vd., (1997) yaptıkları çalışmalarda her üç alt ölçekle yaş arasında anlamlı ilişki olduğunu bildirmişlerdir.

Çalışanların mezun oldukları okula göre MTÖ toplam puan ortalamalarına bakıldığında lise mezunu çalışanların toplam MTÖ puan ortalaması diğer gruplara göre daha yüksek; MTÖ toplam puan ortalamaları lisansüstü grubunda anlamlı olmasa da diğer gruplara göre daha düşük bulunmuştur. Özkan'ın yapmış olduğu çalışmada da, eğitim düzeyi yüksek olanların tükenmişlik düzeylerinin daha düşük olduğunu belirtmiştir (Özkan, 2008: 77-87).

Meslek seçimini bilinçli ve isteyerek yapanların mesleğin gereklerini yerine getirmede daha başarılı olacağı bunun da tükenmişlik sendromunu azaltacağı bilinmektedir (Karadağ vd, 2002: 8-15). Meslek tercihinin yapılması ile MTÖ arasında yapılan analiz sonucunda anlamlı bir farklılık belirlenmiştir. Özellikle isteksiz olarak meslek tercihinde bulunan sağlık çalışanları daha yüksek düzeyde bir tükenmişlik yaşamaktadır. Elde edilen bu sonuç Akyüz'ün ve Altay'ın yapmış olduğu çalışmalar ile uyumlu bir yapıdadır (Akyüz, 2015: 21-34; Altay vd., 2010: 10-16).

Yaşam kalitesi yükseldikçe kişiler yaptıkları işten mutluluk duymakta ve buna bağlı olarak kişilerin iş performansları artmakta ve yaptıkları işte daha başarılı olmaktadırlar (Tütüncü, 2008: 169-199; Perim, 2007: 70-74). Bu araştırmada çalışanların kendi sağlık durumlarını değerlendirmeleri ile WHOQOL-BREF-TR toplam puan ortalaması arasında anlamlı bir farklılık bulunmuştur. Sağlık durumunu iyi hisseden bireylerin toplam puan ortalamalarının yüksek olduğu saptanmıştır. $\mathrm{Bu}$ bulgu 1şığında sağlığın yaşam kalitesini olumlu yönde etkilediği söylenebilir. Yapılan çalışmalarda da bu çalışma bulguları ile benzerlik göstermektedir (Solar, 2008: 68-73; Gülmez, 2013: 1-6). Benzer şekilde Kaya'nın Ankara'da 112 Acil Yardım Hizmetleri sağlık çalışanlarının öznel yaşam kalitelerinin değerlendirilmesi çalışmasında elde edilen sonuçlar çalışmamızı desteklemektedir (Kaya, 2004: 1-14).

WHOQOL-BREF-TR toplam puan ortalaması ile gelir durumu arasındaki farkın anlamlı olduğu bulunmuştur. Yapılan çalışmalarda bireylerin gelir düzeyleri ile yaşam kalitesi arasında anlamlı ilişki saptanmıştır (Oktik, 2004; Acaray ve Pınar, 2004: 1-11; Kalantar-Zadem vd., 2001: 
2797-2806; (Suet-Ching, 2001: 218-227; Aylaz ve Aydın, 2014). Çalışmamızda da aylık geliri yüksek olan bireylerin yaşam kalitesi puanları daha yüksek bulunmuştur. Bir çalışmada da geliri giderine denk olanların yaşam kalitesi sosyal alan puanlarının, geliri giderinden az olanlardan daha yüksek olduğu saptanmıştır (Güngör vd., 2007: 10-18).

$\mathrm{Bu}$ çalışmada tükenmişlik ölçeğinin alt boyutları olan Duygusal Tükenme ve Duyarsızlaşma ile Yaşam Kalitesi alt boyutları arasında pozitif bir ilişki, Kişisel Başarısızlık ile Yaşam Kalitesi alt boyutları arasında ise, negatif bir ilişki olduğu ve tükenmişlik yaşam kalitesini olumsuz etkilediği saptanmıștır. Sağlık çalışanlarıyla yapılan çalışmalarda da tükenmişlik ile yaşam kalitesi arasında anlamlı bir ilişki olduğunu saptamıştır (Yıldırım ve Hacıhasanoğlu, 2011: 6168).

\section{Sonuç}

$\mathrm{Bu}$ çalışmada, hemşirelerin tükenmişlik ve yaşam kalitesinin düşük olduğu ve bazı değişkenlerin (Sağlık değerlendirme durumu, çalıştığı bölüm, meslek seçme durumu) yaşam kalitesini olumsuz yönde etkilediği belirlenmiştir.

Hemşirelerin üretkenliğini arttırmak ve mesleki şartlarını iyileştirmek, sadece sağlık çalışanlarını değil, tüm toplumu olumlu etkileyebilmektedir. $\mathrm{Bu}$ nedenle hemşirelerin mesleki tükenmişliklerinin azaltılmasıyla, üretkenliklerinin de artması mümkün olabilir. Çünkü mesleki tükenmişlik düzeyi, çalışanların iş performansları üzerinde doğrudan etkisi olan önemli bir etkendir. $\mathrm{Bu}$ nedenle hemşirelerin mesleki anlamda üretkenliklerinin arttırılması için, mesleki tükenmişlik düzeylerinin incelenmesi, buna neden olan etkenlerin ortaya konması ve buna göre çözüm önerilerinin getirilmesi büyük önem taşımaktadır

Hemşirelerin tükenmişliği önlemeye ve çözmeye yönelik yöntemlerin daha fazla araştırılması, hemşirelerin daha sağlıklı bir biçimde mesleklerini yapmalarına ve sağlık hizmetlerinin geliştirilmesine katkıda bulunabilir. Hemşirelerin iyi ve sağlıklı bir yaşam kalitesine sahip olmaları, toplumun bütününü de olumlu olarak etkileyecektir. Bu nedenle yaşam kalitesi gerçeğini göz ardi etmeyen, özellikle gelir durumunu iyileştirici bir sağlık politikasının oluşturulması önerilebilir.

Yapılan bu çalışmadan elde edilen bulgular, bir hastanede çalışan hemşireler ile sınırlı olduğundan genellenmemelidir. $\mathrm{Bu}$ çalışmayı referans alarak bundan sonra yapılacak çalışmalara, hemşirelerin yer aldığı daha büyük bir evrende çalışma yapılması bu konuyu bir adım daha öteye taşıyacağı düşünülmektedir.

\section{Kaynakça}

Acaray, A., \& Pınar, R. (2004). Kronik hemodiyaliz hastalarının yaşam kalitesinin değerlendirilmesi. $C \ddot{U}$ Hemşirelik Yüksek Okulu Dergisi, 8(1), 1-11.

Akyüz, İ. (2015). Hemşirelerin tükenmişlik ve depresyon düzeylerinin çalışma koşulları ve demografik özellikler açısından incelenmesi. İşletme ve iktisat çalişmalari dergisi, 3(1), 21-34.

Altay, B., Gönener, D., \& Demirkiran, C. (2010). Bir üniversite hastanesinde çalışan hemşirelerin tükenmişlik düzeyleri ve aile desteğinin etkisi. Fırat Tip Dergisi, 15(1), 10-16.
Arslantas, D., Ünsal, A., Metintas, S., Koc, F., \& Arslantas, A. (2009). Life quality and daily life activities of elderly people in rural areas, Eskişehir (Turkey). Archives of gerontology and geriatrics, 48(2), 127-131.

Aslan, S., \& Aslan, R. Alparslan. ZN, Gürkan. SB ve Ünal. M.(1997)“Hekimlerde Tükenmede Cinsiyetle İlişkili Etkenler”. Çukurova Üniversitesi Tıp Fakültesi Dergisi, 22(2), 132-136.

Aydemir, Ö., \& Köroğlu, E. (2007). Psikiyatride Kullanılan Klinik Ölçekler. 3’üncü baskı. Ankara. Hekimler Yayın Birliği, 346-353.

Aylaz, R., \& Aydın, S. (2014). acil ve diğer servislerde görev yapan sağlik çalişanlarinin vardiyali çalişmasinin yaşam kalitesi üzerine etkisi. yildirim beyazit üniversitesi hemşirelik e-dergisi, 2(3).

Barron, D. N., \& West, E. (2007). The emotional costs of caring incurred by men and women in the British labour market. Social Science \& Medicine, 65(10), 2160-2171.

Brewer, E. W., \& Shapard, L. (2004). Employee burnout: A meta-analysis of the relationship between age or years of experience. Human resource development review, 3(2), 102-123.

Cimete, G., Gencalp, N. S., \& Keskin, G. (2003). Quality of life and job satisfaction of nurses. Journal of Nursing Care Quality, 18(2), 151-158.

Çimen, M., \& Ergin, C. (2001). Türk Silahlı Kuvvetleri sağlık personelinin tükenmişlik düzeylerinin incelenmesi. Gülhane Tıp Dergisi, 43(2), 169-176.

Demir, A., Ulusoy, M., \& Ulusoy, M. (2003). Investigation of factors influencing burnout levels in the professional and private lives of nurses. International journal of nursing studies, 40(8), 807-827.

Ergin, C. (1992). Doktor Ve Hemşirelerde Tükenmişlik ve Maslach Tükenmişlik Envanterinin Uyarlanması. 7. Ulusal Psikoloji Kongresi, Ankara.

Ergin, C. (1995). Akademisyenlerde tükenmişlik ve çeşitli stres kaynaklarının incelenmesi. Edebiyat Fakültesi Dergisi, 12(1-2).

Ergin, C. (1996). Maslach tükenmişlik ölçeğinin Türkiye sağlık personeli normları. 3P Dergisi, 4(1), 28-33.

Ergin, D., Celasin, N., Akış, Ş., Altan, Ö., Bakırlığlu, Ö., \& Bozkurt, S. (2009). Dahili kliniklerde görev yapan hemşirelerin tükenme ve empatik beceri düzeyleri ve bunları etkileyen faktörlerin belirlenmesi. Fırat Sağlık Hizmetleri Dergisi, 4(11), 49-64.

Ergün, A., Eti Aslan, F., Vatan, F., Olgun, N., \& Kuğuoğlu, S. (2013). Sağlık bakımındaki gelişmeler ve bakım uygulamaları. İçinde: Eti Aslan $F$, Karadakovan A,(Eds.), Dahili ve cerrahi hastallklarda bakım. Adana: Nobel Kitabevi.

Erol, A., Sariçiçek, A., \& Gülseren, Ş. (2007). Asistan hekimlerde tükenmişlik: İş doyumu ve depresyonla ilişkisi. Anadolu Psikiyatri Dergisi.8,241-247)

Eser, E., Fidaner, H., Fidaner, C., Eser, S., Elbi, H., \& Göker, E. (1999a). Psychometric properties of the WHOQOL- 
100 and WHOQOL-BREF. J Psychiatry Psychol Psychopharmacol, 7(2), 23-40.

Eser, E., Fidaner, H., Fidaner, C., Eser, S. Y., Elbi, H., \& Göker, E. (1999b). WHOQOL-BREF TR: a suitable instrument for the assessment of quality of life for use in the health care settings in Turkey. Quality of Life Research, 647.

Gülmez, H. (2013). Çalışanların yaşam kalitesini etkileyen faktörler. Turkish Journal of Family Medicine and Primary Care, 7(4), 1-6

Güneş, N., \& Üstün, B. (2008). Bir üniversite hastanesinde çalişan hemşirelerin tükenmişlik düzeyi ve etkileyen faktörlerin incelenmesi. Journal of Anatolia Nursing and Health Sciences, 11(4), 48-56.

Güngör, N., Çiray, N., Vatansever, Ş., \& Akyol, A. D. (2007). Yoğun Bakım Hemşirelerinin Yaşam Kalitesi, İş Doyumu ve Tükenmişlik Düzeylerinin Saptanması. Yoğun Bakım Hemşireliği Dergisi,11(1):10-18

Kalantar-Zadeh, K., Kopple, J. D., Block, G., \& Humphreys, M. H. (2001). Association among SF36 quality of life measures and nutrition, hospitalization, and mortality in hemodialysis. Journal of the American Society of Nephrology, 12(12), 2797-2806.

Karadağ, G., Sertbaş, G., Güner, İ., Taşdemir, H., \& Özdemir, N. (2002). Hemşirelerin iş doyumu ve tükenmişlik düzeyleri ile bunları etkileyen bazı değişkenlerin incelenmesi. Hemşirelik Forumu, 5(6), 815 .

Kavlu, İ., \& Pinar, R. (2009). Acil servislerde çalışan hemşirelerin tükenmişlik ve iş doyumlarının yaşam kalitesine etkisi. Turkiye Klinikleri Journal of Medical Sciences, 29(6), 1543-1555.

Kaya, M. (2004). Ankara'da 112 Acil Yardım Hizmetleri Sağlık Çalışanlarının Öznel Yaşam Kalitelerinin Değerlendirilmesi. Sağlık ve Toplum Dergisi, 4, 1-14.

Kırılmaz, A. Y., Çelen, Ü., \& Sarp, N. (2003). Ilkögretimde Çalisan bir Ögretmen Grubunda "Tükenmislik Durumu" Arastirmasi. İlköğretim Online, 2(1), 2-9.

Martin, F., Poyen, D., Bouderlique, E., Gouvernet, J., Rivet, B., Disdier, P., . . S Scotto, J.-C. (1997). Depression and burnout in hospital health care professionals. International Journal of Occupational and Environmental Health, 3(3), 204-209.

Maslach, Schaufeli, W. B., \& Leiter, M. P. (2001). Job burnout. Annual review of psychology, 52(1), 397-422.

Maslach, C. Ve PG Zimbardo (1982),"Burnout-The Cost of Caring": Prentice-Hall, Inc., Englewood Cliffs, New Jersey.

Maslach, C., \& Jackson, S. E. (1981). The measurement of experienced burnout. Journal of organizational behavior, 2(2), 99-113.

Oktik, N. (2004). Huzur evinde yaşam ve yaşam kalitesi: Muğla örneği, Muğla Üniversitesi yayınları; 52.

Olcay, Ç. (2001). The burnout in nursing academicians in Turkey. International journal of nursing studies, 38(2), 201-207.
Özkan, Ş. (2008). Rol çatışması ve rol belirsizliğinin hekim ve hemşirelerin tükenmişlik düzeyleri üzerine olan etkileri. Hacettepe Üniversitesi, Ankara, 77-87

Perim, A. (2007). Trakya Üniversitesi Eğitim, Araştırma ve Uygulama Hastanesi'nde Çalışan Hemşirelerin Kaliteli Yaşam Algısının Belirlenmesi, 70-74

Raftopoulos, V., Charalambous, A., \& Talias, M. (2012). The factors associated with the burnout syndrome and fatigue in Cypriot nurses: a census report. BMC Public Health, 12(1), 457.

Sayil, I., Haran, S., Ölmez, Ş., \& Özgüven, H. D. (1997). Ankara Üniversitesi hastanelerinde çalışan doktor ve hemşirelerin tükenmişlik düzeyleri. Kriz dergisi, 5(2), 71-77.

Solar, M. (2008). Sigara içme Durumunun Üniversite Öğrencilerinin Yaşam Kalitesi Üzerine Etkisinin incelenmesi. Toraks Dergisi, 9(2), 68-73.

Suet-Ching, W. L. (2001). The quality of life for Hong Kong dialysis patients. Journal of advanced nursing, 35(2), 218-227.

Suran, B. G., \& Sheridan, E. P. (1985). Management of burnout: Training psychologists in professional life span perspectives. Professional Psychology: Research and Practice, 16(6), 741.

Şahin, D. S., Özgür, Ö., Kılınç, A. S., Sütlü, S. P., \& Mutluay, D. (2014). Acil Servis ve Yoğun Bakım Hemşirelerinin Yaşam Kalitesinin Değerlendirilmesi. Mehmet Akif Ersoy Üniversitesi Să̆lık Bilimleri Enstitüsü Dergisi, 2(2), 81-92.

Şenturan, L., Gülseven-Karabacak, B., Ecevit-Alpar, Ş., \& Sabuncu, N. (2009). Hemodiyaliz ünitelerinde çalışan hemşirelerin tükenmişlik düzeyi. Maltepe Üniversitesi Hemşirelik Bilim ve Sanatı Dergisi, 2(2), 33-45.

Taycan, O., Kutlu, L., Çimen, S., \& Aydın, N. (2006). Bir üniversite hastanesinde çalışan hemşirelerde depresyon ve tükenmişlik düzeyinin sosyodemografik özelliklerle ilişkisi. Anadolu Psikiyatri Dergisi, 7(2), 100-108.

Testa, M. A., \& Simonson, D. C. (1996). Assessment of quality-of-life outcomes. New England journal of medicine, 334(13), 835-840.

Tunçel, Y. İ., Kaya, M., Kuru, R. N., Mentes, S., \& Ünver, S. (2014). Onkoloji Hastanesi Yogun Bakim Ünitesinde Hemsirelerin Tükenmislik Sendromu/Nurses' Burnout in Oncology Hospital Critical Care Unit. Turk Yogun Bakim Dernegi Dergisi, 12(2), 57.

Tütüncü, Ö. (2008). SA 8000 Sosyal Sorumluluk Standardı ile İş Yaşamı Kalitesi Arasındaki İlişki. Dokuz Eylül Üniversitesi Sosyal Bilimler Enstitüsü Dergisi, 10(2), 169-199.

Wright, T. A., \& Bonett, D. G. (1997). The contribution of burnout to work performance. Journal of organizational Behavior, 491-499.

Yıldırım, A., \& Hacıhasanoğlu, R. (2011). Sağlık çalışanlarında yaşam kalitesi ve etkileyen değişkenler. Journal of Psychiatric nursing, 2(2), 61-68. 
Yılmaz, E. (2014). Serbest Muhasebeci Mali Müşavirlerin Mesleki Tükenmişlik Düzeyleri İle İşe Bağlilik Düzeyleri Arasindaki İlişki: Samsun İlinde Bir Araştirma. Muhasebe ve Vergi Uygulamalari Dergisi $(M U V U) / J o u r n a l$ of Accounting \& Taxation Studies (JATS), 7(3), 59-63.

Yüksel, İ. (2011). Çalışma yaşamı kalitesinin tipik ve atipik istihdam açısından incelenmesi. Doğuş Üniversitesi Dergisi, 5(1), 47-58.

Zorba, Y. (2016). Tükenmişlik Sendromu: Gemi Kaptanlari Ve Güverte Zabitleri Üzerine Tanimlayici Bir Çalişma. Dokuz Eylül Üniversitesi Denizcilik Fakültesi Dergisi, 8(1), 108-111. 